\title{
Exploring one aspect of pedagogical content knowledge of teaching assistants using the test of understanding graphs in kinematics
}

\author{
Alexandru Maries* and Chandralekha Singh \\ Department of Physics and Astronomy, University of Pittsburgh, Pittsburgh, Pennsylvania 15260, USA
}

(Received 24 June 2013; published 13 November 2013)

\begin{abstract}
The Test of Understanding Graphs in Kinematics (TUG-K) is a multiple-choice test developed by Beichner in 1994 to assess students' understanding of kinematics graphs. Many of the items on the TUG-K have strong distractor choices which correspond to students' common difficulties with kinematics graphs. Instruction is unlikely to be effective if instructors do not know the common difficulties of introductory physics students and explicitly take them into account in their instructional design. We evaluate one aspect of the pedagogical content knowledge of first-year physics graduate students enrolled in a teaching assistant training course related to topics covered in the TUG-K. In particular, for each item on the TUG-K, the graduate students were asked to identify which incorrect answer choice they thought would be most commonly selected by introductory physics students if they did not know the correct answer after instruction in relevant concepts. We used the graduate student data and the data from Beichner's original paper for introductory physics students (which was collected from over 500 college and high school students) to assess this aspect of the pedagogical content knowledge of the graduate students, i.e., knowledge of student difficulties related to kinematics graphs as they are revealed by the TUG-K. We find that, although the graduate students, on average, performed better than random guessing at identifying introductory student difficulties on the TUG-K, they did not identify many common difficulties that introductory students have with graphs in kinematics. In addition, we find that the ability of graduate students to identify the difficulties of introductory students is context dependent and that discussions among the graduate students improved their understanding of student difficulties related to kinematics graphs. Moreover, we find that the ability of American graduate students in identifying common student difficulties is comparable with that of foreign graduate students.
\end{abstract}

DOI: 10.1103/PhysRevSTPER.9.020120

PACS numbers: 01.40.Fk, 01.40.gb

\section{INTRODUCTION}

The Test of Understanding Graphs in Kinematics (TUG-K) [1] is one of many multiple-choice tests designed to assess conceptual understanding in introductory physics [2-11]. Some of these tests, e.g., the Force Concept Inventory [3], have been widely used by instructors and education researchers for various purposes, for example, to identify student difficulties [2,12], to compare the effectiveness of curricula and pedagogies [13], and to investigate gender differences $[14,15]$. The TUG-K was developed by Beichner to assess students' understanding of kinematics graphs after early physics education research which revealed that introductory physics students have many difficulties with constructing and interpreting graphs in kinematics [1,16-24]. Helping introductory physics students become facile with different representations of concepts is a critical component of the development of expertise in physics. Facility with graphical representations

\footnotetext{
*hitren86@gmail.com

Published by the American Physical Society under the terms of the Creative Commons Attribution 3.0 License. Further distribution of this work must maintain attribution to the author(s) and the published article's title, journal citation, and DOI.
}

is particularly important and this representation has been emphasized extensively in research-based instructional tools, e.g., in multimedia learning modules [25-27].

The TUG-K was developed by taking the common difficulties of introductory students in interpreting graphs, revealed by research, into consideration and many items on the test include strong distractor choices which uncover that some difficulties are very common. Beichner subjected the test to much statistical analysis (including calculation of KR-20, point biserial coefficients, Ferguson's delta, and others) to ensure that it is a reliable instrument for assessing understanding of kinematics graphs. In addition, in the construction phase of the test, he asked many educators at different institutions for feedback on the items on the test in order to ensure content validity.

There are several theoretical frameworks that inspire our research and focus on the importance of instructors familiarizing themselves with students' prior knowledge (including what students learn from traditional instruction) in order to scaffold their learning with appropriate curricula and pedagogies. In the context of this study, they point to the importance of being knowledgeable about student difficulties in order to help students learn better. For example, Piaget [28] emphasized "optimal mismatch" between what the student knows and where the instruction 
should be targeted in order for desired assimilation and accommodation of knowledge to occur. A related framework is the theory of conceptual change put forth by Posner et al. [29]. In this model, they suggest that conceptual changes or "accommodations" can occur when the existing concepts students have are not sufficient for or are inconsistent with new phenomena. They also suggest that these accommodations can be very difficult for students, particularly when students are firmly committed to their prior understanding. This model suggests that it is important for instructors to be knowledgeable about student ideas, which, when applied to particular physics contexts, can lead to difficulties. Within this model, if students are motivated by an anomaly which provides a cognitive conflict that illustrates how their conceptions are inadequate in explaining a newly encountered physical situation, they can become dissatisfied with their current concepts and improve their understanding. But instructors must be aware of what conceptions students have and what difficulties these conceptions can lead to in order to design a task that produces the desired cognitive conflict.

The research presented here uses the TUG-K (along with the original student data in Ref. [1]) to explore one aspect of the pedagogical content knowledge (PCK) of first-year graduate students, namely, knowledge of common introductory student difficulties. The graduate students were enrolled in a semester-long teaching assistant (TA) training course at the University of Pittsburgh (Pitt). Towards the end of the semester, the graduate students performed a task which used the TUG-K survey to investigate how knowledgeable the graduate students are about common student difficulties related to graphical representations of motion. For each item on the TUG-K, the graduate students were asked to identify which one of the four incorrect answer choices was, in their view, the most common incorrect answer choice of introductory physics students if they did not know the correct answer after instruction in relevant content. The graduate students first carried out this task individually followed by repeating the task in groups of two or three. A class discussion related to their responses followed these exercises.

Pedagogical content knowledge is a term coined by Shulman [30,31] to mean the subject matter knowledge for teaching, and many researchers in K-16 education have used this construct [32-36]. Shulman defines PCK as "a form of practical knowledge which guides the pedagogical practices of educators in highly contextualized settings" [30]. According to Shulman, PCK is composed of the most useful forms of representations of the topics and concepts, powerful analogies, illustrations and examples, and "understanding of what makes the learning of specific topics easy or difficult" [30]. Therefore, knowledge of student difficulties is an important aspect of PCK and the research presented here was designed to explore this aspect of the PCK of graduate students: knowledge of common introductory student difficulties with kinematics graphs identified by the TUG-K. We refer to this as the "TUG-K related PCK" of graduate students. The graduate students who teach recitations for introductory physics courses typically have a closer association with introductory students than the course instructors because they hold regular office hours and interact with introductory students in the physics resource room at Pitt where they help introductory students. In addition, recitation sizes are usually much smaller than the sizes of lecture classes taught by instructors. Therefore, TAs who are knowledgeable about introductory student difficulties in interpreting kinematics graphs can play a significant role in improving introductory student understanding of kinematics and they can address these difficulties directly in their interactions with students. Of course, it is also important for instructors to be knowledgeable of student difficulties in order to design instruction to effectively address and remedy these difficulties.

\section{RESEARCH QUESTIONS: PERFORMANCE OF GRADUATE STUDENTS AT IDENTIFYING INTRODUCTORY PHYSICS STUDENTS' DIFFICULTIES RELATED TO KINEMATICS GRAPHS ON THE TUG-K}

The following research questions were developed for the purpose of investigating the TUG-K related PCK of graduate students:

I. To what extent are American physics graduate students, who have been exposed to undergraduate teaching in the United States, better at identifying introductory student difficulties than foreign physics graduate students?

Graduate programs across the U.S. are populated by many foreign graduate students. According to recent American Institute of Physics (AIP) statistics, almost half of the firstyear physics graduate students in U.S. universities are nonU.S. citizens [37], and more than half of the awarded physics Ph.D.'s are to non-U.S. citizens [38]. A majority of physics departments in the U.S. require that graduate students become TAs for undergraduate courses at least for one or two semesters. Since the influence of foreign graduate students in physics undergraduate education is becoming commensurate (at least in terms of numbers of TAs) with that of American graduate students, it is worthwhile comparing the knowledge that these two different groups of graduate students have regarding introductory student difficulties with physics. The educational backgrounds of these two groups of graduate students are very different, and it is unclear whether these backgrounds have a significant effect on developing an understanding of the difficulties of introductory physics students with physics content, in particular, with kinematics graphs for our research presented here.

II. To what extent do graduate students identify introductory students' difficulties more often when working 
in groups than when working individually? (i.e., do discussions improve graduate students' understanding of introductory students' difficulties with kinematic graphs?)

Peer discussions have been found to be productive in the context of learning physics [12,39]. It is useful to investigate whether discussions with peers are also productive in the context of learning about student difficulties related to kinematics concepts.

III. To what extent do graduate students identify "major" introductory student difficulties compared to "moderate" ones? (Major and moderate difficulties are defined later.)

Research in physics education has shown that introductory students encounter many common difficulties in learning physics that must be taken into account in the design of curricula and pedagogies to help students build good mental models. These difficulties are of varying degrees, and while one may assume that the more common difficulties are easier to identify, this may not be true. In particular, in a particular content area, cognitive task analysis of the underlying knowledge from the expert perspective can fail to identify common difficulties that are actually found via research. Therefore, in the context of difficulties with kinematics graphs, we investigated to what extent the major difficulties of introductory students were identified by graduate students compared to the moderate ones.

IV. To what extent do graduate students identify specific introductory student difficulties with kinematic graphs? Is their ability to identify these difficulties context dependent? (A particular graphical concept is probed in different contexts in different questions on TUG-K.)

The TUG-K reveals several different types of student difficulties with kinematics graphs which are identified by student responses to several questions. We investigated the extent to which graduate students are able to identify specific difficulties of introductory students. Physics education research has shown that introductory student performance is context dependent; i.e., correct application of physics concepts depends on the contexts of the questions posed. Here, we investigate whether the ability of graduate students to identify common introductory student difficulties is also context dependent.

For multiple-choice questions, the context is composed of both the physical situation presented in the problem and the answer choices because different answer choices can change the difficulty of a question. For example, a multiple-choice question is easier for introductory students if the incorrect answer choices are not chosen to reflect common student difficulties, and are challenging for students when they are chosen to reflect common difficulties $[2,3]$. For the TUG-K, our use of the term context refers to the type of graph presented (position, velocity, acceleration), the type of task (conceptual versus quantitative), and the answer choices. A conceptual and a quantitative question posed with the same type of graph provide different contexts (for example, items 2 and 6 on the TUG-K). Similarly, two quantitative questions with the same type of graph provide different contexts if their answer choices do not reflect the same type of student difficulties (for example, items 6 and 7 on the TUG-K: item 6 provides an answer choice which corresponds to the student difficulty related to computing slopes by calculating $y / x$ instead of $\Delta y / \Delta x$, but item 7 does not use this type of answer choice).

\section{METHODOLOGY}

\section{A. Materials and participants}

The materials used for this study were the TUG-K survey developed by Beichner along with the data in Beichner's original paper [1] which was collected from more than 500 college and high school students.

The participants of this study were 25 first-year physics graduate students enrolled in a TA training class in their first semester in graduate school. The TA training class is a pedagogy oriented semester-long course which is required of all first-year graduate students at Pitt. The course meets once a week for two hours and is designed to help graduate students be more effective teachers. During the course, students learn about cognitive research and physics education research and discuss their instructional implications. Students are also introduced to curricula and pedagogies based on physics education research which stress the importance of being knowledgeable about introductory students' difficulties in order to help them transition toward expertise. Each graduate student also discusses the solution of a physics problem in the class in the manner in which they would discuss it if they were teaching introductory students and they receive feedback from the other graduate students and the instructor. Also, during the course, students complete various reflective exercises aimed at helping them perform their TA duties in a student-centered manner.

All but three of the graduate students who participated in this study were teaching introductory physics recitations or labs for the first time. Two of the three who were not teaching had physics teaching experience as undergraduates, either as a teaching assistant or as a tutor for introductory physics courses. Only one student did not have teaching experience with physics, but this student tutored mathematics as an undergraduate. Also, in the TA training course introductory student difficulties were discussed, however, not in the specific context of interpreting kinematics graphs (until after students completed all tasks related to the TUG-K as described below).

\section{B. Methods}

Toward the end of the TA training class (so that a majority of graduate students had almost a semester worth of teaching experience), the graduate students were asked to complete three different tasks related to the TUG-K: 
(1) while working individually, they were asked to identify the correct answers for each question; (2) while working individually, for each question on the TUG-K, they were asked to identify which one of the four incorrect answer choices, in their view, would be most commonly selected by introductory physics students after instruction in relevant concepts if the introductory students did not know the correct answers; and (3) they repeated the second task, except working in groups of two or three. The graduate students performed task (1) first, then task (2), and finally task (3) followed by a class discussion during a two hour TA training class. We refer to tasks (2) and (3) as individual and group TUG-K related PCK tasks. The graduate students were allowed as much time as they needed for each task. All graduate students finished the first task within the first 30 minutes and the second task within the first hour. The third task (group work) was completed by all groups within 40 minutes followed by a full class discussion about the PCK task.

In order to investigate the TUG-K related PCK of graduate students, scores were assigned to each graduate student as follows: a graduate student who selected a particular answer choice in a particular question received a score which was the fraction of introductory students who selected that particular answer choice. If a graduate student selected the correct answer choice, they would be assigned a score of zero because they were explicitly asked to indicate which incorrect answer choice is most commonly selected by introductory students. For example, on question 1 , the percentages of introductory students who selected A, B, C, D, and E are $40 \%, 16 \%, 4 \%, 22 \%$, and 17\%, respectively (see Fig. 1 in the Appendix). Answer choice B is correct; thus, the score assigned for each answer choice on question 1 was $0.4,0,0.04,0.22$, and 0.17 (A, B, C, D, and E). The score a graduate student would obtain on this PCK task for the whole test can be obtained by summing over all of the questions. A mathematical description of how this calculation was performed is included in the Appendix.

In order to determine whether the graduate students performed better than random guessing on the TUG-K related PCK task, a population of random guessers was generated. The population was generated by choosing $N=24$ "random guessers" in order to have a reasonable group size when performing $t$-tests [40]. Random guessing on this task would correspond to selecting one of the four incorrect answer choices for each question with equal probability $(25 \%)$. Therefore, one quarter of the random guessers always selected the first incorrect answer choice, one quarter selected the second incorrect answer choice, etc. Since the graduate students were not told the correct answers before they performed the TUG-K related PCK task, random guessing would not perfectly correspond to selecting one of the four incorrect answer choices with equal probability. For a particular question, there is a small probability that a graduate student does not know the correct answer. However, our data indicate that this probability is very small because, in all but two questions, at least 24 out of 25 graduate students knew the correct answers. In the other two questions, 23 out of 25 and 22 out of 25 of the graduate students knew the correct answers (see Fig. 1 included in the Appendix). Moreover, since for a given question, one quarter of the random guessers selected each of the four incorrect answer choices, one can calculate a mean and a standard deviation that can be used to perform comparison with the graduate student scores. Furthermore, our choice of random guessers maximizes the standard deviation.

We note that our approach to determine the TUG-K related PCK score of graduate students weighs the responses of graduate students by the percentage of introductory students who selected a particular incorrect response. This weighing scheme was chosen because the more prevalent an introductory student difficulty is, the more important it is for the graduate students to be aware of it and take it into account in their instruction.

\section{Approach for answering the research questions}

The researchers analyzed whether graduate students performed better at identifying introductory students' difficulties on the TUG-K than random guessing by performing statistical analysis.

I. To what extent are American physics graduate students, who have been exposed to undergraduate teaching in the United States, better at identifying introductory student difficulties than foreign physics graduate students?

Out of the 25 first-year graduate students who participated in this study, nine were American, nine were Chinese, and seven were from other foreign countries (Asia and Europe). The PCK scores of three groups of graduate students were compared (American, Chinese, and other foreign students). The reason we divided the graduate students in three groups is because the American graduate students were exposed to teaching in the U.S. as opposed to the foreign students, who were not exposed to U.S. teaching practices before graduate school and many were taught physics in their own native languages. The nine Chinese graduate students were placed in a separate group because, although they fit the category of foreign graduate students, it is possible that their backgrounds are different from the backgrounds of most of the other foreign graduate students.

II. To what extent do graduate students identify introductory students' difficulties more often when working in groups than when working individually? (i.e., do discussions improve graduate students' understanding of introductory students' difficulties with kinematic graphs?) 
Previous studies have found that introductory students exhibit improved performance and conceptual understanding after engaging in discussions with one another [12,39]. We investigated whether discussions among graduate students related to introductory student difficulties improve their PCK performance related to kinematics graphs. Since the graduate students first performed the TUG-K related PCK task individually and then in groups, we investigated whether their PCK performance increased in the group exercise compared to the individual exercise. In addition, we investigated whether the discussions shifted graduate students' selections towards more common introductory student incorrect answer choices. In particular, we identified how often two or three graduate students who worked together in the group TUG-K related PCK task, when completing the individual task, did not select the same answer as the most common difficulty with that question and when completing the group task selected an answer choice which was connected to a more common (by $5 \%$ or more) introductory student difficulty.

III. To what extent do graduate students identify "major" introductory student difficulties compared to "moderate" ones?

Most of the questions on the TUG-K have strong distractor choices that are selected by many introductory students even after instruction. The researchers selected a heuristic such that an incorrect answer choice was connected to a major student difficulty if more than $33 \%$ (or $1 / 3$ ) of introductory students selected that answer choice. An incorrect answer choice was considered to be connected to a moderate difficulty if between $20 \%$ and $33 \%$ of the introductory students selected that answer choice. In order to answer this research question, the average TUG-K related PCK scores of graduate students on questions that had major difficulties were compared to the average scores on questions that had moderate difficulties. However, for each question, the minimum and maximum possible scores are different because they correspond to the smallest and largest fraction of introductory students who select a particular incorrect answer choice. Therefore, for each question, the average score of graduate students was normalized to be on a scale from zero to a maximum possible score of 100 in order to make a comparison between different questions (see Fig. 2). This was done for each question in the following manner: graduate student normalized score $=100 \times($ graduate student average PCK score - minimum possible score)/(maximum possible score - minimum possible score). The normalized graduate student score on a particular question on the TUG-K is then zero if they obtained the minimum possible score and 100 if they obtained the maximum possible score.

IV. To what extent do graduate students identify specific introductory student difficulties with kinematic graphs? Is their ability to identify these difficulties context dependent?
This question was answered by identifying common introductory student difficulties on different questions and analyzing graduate students' PCK performance in identifying these common difficulties in different contexts.

\section{RESULTS}

Analysis of the PCK performance of the graduate students was performed on each of the questions on the TUG-K which revealed a moderate or major introductory student difficulty and it is shown in Figs. 1 and 2 (included in the Appendix). Figure 1 shows the percentages of introductory physics students and graduate students who selected each answer choice in each question on the TUG-K. The introductory students were asked to identify the correct answers, and the graduate students were asked to identify the incorrect answers which, in their view, were most common among introductory students for each question after instruction in relevant concepts. In Fig. 1, correct answers are indicated by the green shading, major introductory student difficulties (incorrect answer choices selected by more than $33 \%$ of the introductory students) are indicated by red shading, and moderate difficulties are shown in red font. In addition, the second column ( $>$ RG) indicates whether the graduate students performed better than random guessing on each question (yes or no).

Figure 2 shows the normalized average TUG-K related PCK score (on a scale from 0 to 100) for the graduate students on each question that had moderate or major difficulties. The TUG-K related PCK performance of the graduate students on a given question was considered "good" (shaded green) if their normalized average PCK score is $67 \%$ or more of the maximum possible score, "moderate" (shaded yellow) if their normalized average PCK score is between $50 \%$ and $67 \%$ of the maximum possible score, and "poor" (shaded red) if their normalized average PCK score is less than 50\% of the maximum possible score. These cutoffs were selected based on the normalized scores of the graduate students. The scores were put in order from smallest to largest and the bottom $1 / 3$ of the scores correspond to poor performance, the middle $1 / 3$ correspond to moderate performance, and the top $1 / 3$ of the scores correspond to good performance. Moreover, in Fig. 2 , for questions that had moderate difficulties, the question numbers are in red font, and for questions that had major difficulties the question numbers are shaded red.

I. To what extent are American physics graduate students, who have been exposed to undergraduate teaching in the United States, better at identifying introductory student difficulties than foreign physics graduate students?

In order to answer this question, we compared the average PCK scores of different subgroups of graduate students. As noted earlier, the maximum PCK score on this task for any given question that a graduate student could obtain is the largest percentage of introductory students who selected a particular incorrect answer choice. 
TABLE I. Numbers of American, Chinese, and other foreign graduate students, their averages (and percentage of those averages out of the maximum PCK score) and standard deviations (SD) for the PCK scores obtained for determining introductory student difficulties on the TUG-K out of a maximum PCK score of 6.70 .

\begin{tabular}{llll}
\hline \hline & $N$ & Average & SD \\
\hline American & 9 & $4.00(60 \%)$ & 0.54 \\
Chinese & 9 & $4.24(63 \%)$ & 0.55 \\
Other foreign & 7 & $4.46(66 \%)$ & 0.59 \\
\hline \hline
\end{tabular}

The maximum PCK score on this task for the whole test is the sum of all these percentages, which turns out to be 6.70 . Table I shows the averages and standard deviations of the PCK scores of the three different groups of graduate students. The group sizes are too small for meaningful statistics to be extracted from the data. However, it appears that the averages of the American, Chinese, and other foreign graduate students $(60 \%, 63 \%$, and $66 \%$ of the maximum PCK score, 6.70, respectively) are comparable. Therefore, it appears that American graduate students do not perform better at identifying introductory student difficulties (in fact, their average performance was somewhat lower than the performance of the foreign graduate students).

II. To what extent do graduate students identify introductory students' difficulties more often when working in groups than when working individually? (i.e., do discussions improve graduate students' understanding of introductory student difficulties with kinematics graphs?)

(1) Graduate student TUG-K related PCK performance is significantly better when they worked in groups compared to when they worked individually

Table II shows that the performance of graduate students when they worked in groups was better than when they worked individually. A $t$-test indicates that the difference in performance is statistically significant $(p=0.033)$. In addition, calculation of Cohen's $d$ [40] gives a reasonable effect size of 0.78 .

(2) Discussions among graduate students tend to converge on a more common introductory student difficulty

We investigated how often graduate students who selected different answers in the individual TUG-K related PCK task, while working in groups, selected a "better" answer (i.e., an incorrect answer choice which was connected to a more common, by $5 \%$ or more, introductory student difficulty). There were 74 instances in which two or three graduate students who did not all select the same answer in the individual TUG-K related PCK task (while identifying common introductory student difficulties) converged to one answer. In 45 of those instances (61\%), they selected the incorrect answer which was more common (by $5 \%$ or
TABLE II. Number of graduate students and groups, averages (and percentage of those averages out of the maximum PCK score), and standard deviations for the PCK scores obtained for identifying the most common introductory student difficulties on the TUG-K out of a maximum PCK score of 6.70 .

\begin{tabular}{lccc}
\hline \hline Individual & $N$ & Average & SD \\
& 25 & $4.21(63 \%)$ & 0.57 \\
Group & $N$ & Average & SD \\
& 12 & $4.67(70 \%)$ & 0.59 \\
\hline \hline
\end{tabular}

more) among introductory students who did not know the correct answer. It therefore appears that discussions among graduate students were productive and led to a better understanding of introductory student difficulties related to kinematics graphs.

III. To what extent do graduate students identify "major" student difficulties compared to "moderate" ones?

As mentioned earlier, moderate difficulties were considered to be connected to incorrect answer choices selected by between $20 \%$ and $33 \%$ of introductory students, while major difficulties were those had by more than $33 \%$ of introductory students. There are 17 questions on the TUG-K which fit at least one of these two criteria (see Fig. 1 or Fig. 2), eight of which have major introductory student difficulties and nine of which have moderate difficulties. Figure 2 shows that the four questions on the TUG-K with the lowest graduate student PCK performance (questions 6, 8, 9, and 17) all contain a major introductory student difficulty. Moreover, the average PCK score of graduate students on the questions that had major difficulties is $48 \%$ compared to $61 \%$ on the questions that had moderate difficulties. It appears that the average graduate student TUG-K related PCK performance is better by $13 \%$ on questions with moderate introductory student difficulties than on questions with major ones. In other words, overall, graduate students identified moderate difficulties better than major ones.

IV. To what extent do graduate students identify specific introductory student difficulties? Is their ability to identify these difficulties context dependent?

This question was answered by identifying common introductory student difficulties along with the questions in which these difficulties occurred and analyzing the graduate student TUG-K related PCK performance on those questions. Whenever a particular difficulty occurred in more than one question, it was investigated whether the PCK performance of graduate students was context dependent in that it was significantly different on different questions which had different contexts. We note that any interpretation of student difficulties presented here is taken from the original TUG-K paper. The focus of this research is not to discuss these difficulties, but to discuss the performance of the graduate students in identifying them. 
TABLE III. Introductory student difficulty that graphs of time dependence of different kinematics variables that correspond to the same motion should look the same, items on the TUG-K which uncover this difficulty (TUG-K item no.), percentage of introductory students who answer the items incorrectly (\% overall incorrect), incorrect answer choices which uncover this difficulty, percentage of introductory students who have this difficulty based on their selection of these answer choices (\% intro. stud. diff.), and percentage of graduate students who select these answer choices as the most common incorrect answer choices of introductory students (GS \%). For convenience, short descriptions of the questions are given underneath.

\begin{tabular}{lcccr}
\hline \hline Introductory student difficulty & $\begin{array}{c}\text { TUG-K } \\
\text { item no. }\end{array}$ & $\begin{array}{c}\% \text { overall } \\
\text { incorrect }\end{array}$ & $\begin{array}{c}\text { Incorrect } \\
\text { answer choices }\end{array}$ & $\begin{array}{c}\% \text { intro. } \\
\text { stud. diff. }\end{array}$ \\
\hline Graphs of time dependence of different & 11 & 64 & A & 28 \\
kinematics variables that correspond to the & 14 & 52 & A & 25 \\
same motion should look the same & 15 & 71 & B & 24 \\
\hline
\end{tabular}

11. Given a displacement-time graph, identify the velocity vs time graph that represents the same motion

14. Given a velocity-time graph, identify the acceleration vs time graph that represents the same motion

15. Given an acceleration-time graph, identify the velocity vs time graph that represents the same motion

Very few graduate students identified the common introductory student difficulty that graphs of time dependence of different kinematics variables that correspond to the same motion should look the same.

As mentioned by Beichner [1], the common difficulty of students in distinguishing between different kinematics variables is evidenced by the fact that some students claimed that the time dependence of different kinematics variables that correspond to the same motion should look the same. Table III shows that this difficulty was identified by very few graduate students on each of the three questions in which it occurs. The answer choices which uncover this difficulty (choice A for questions 11 and 14 and choice $B$ for question 15 ) were selected by roughly $25 \%$ of introductory students; however, these answer choices were rarely selected by graduate students in the PCK task (see Table III). The highest percentage of graduate students who selected any of these three incorrect answer choices was $16 \%$ on question 14 . Beichner noted [1] that these three questions are the ones with the highest discrimination indices (introductory physics students who answered these questions correctly performed well on the whole test), and he argued that this could be interpreted to mean that this difficulty is the one most critical to address to improve introductory students' understanding of kinematic graphs. However, our analysis suggests that graduate students are largely unaware that this difficulty exists and they are therefore unlikely to address it directly while performing their teaching duties as TAs. Many graduate students expressed astonishment in the discussions that followed the task that introductory physics students would have these difficulties.

The introductory students' difficulty that determining slopes does not require examining initial conditions was identified by very few graduate students, while other diffculties related to determining slopes were identified by more graduate students.

Table IV shows that both questions 6 and 17 had incorrect answer choices selected by $46 \%$ of introductory students but identified by few graduate students. Again, discussions with the graduate students after they carried out the TUG-K related PCK task suggest that many of them were very surprised that introductory students would often not examine initial conditions when determining slopes. The graduate students were more likely to think that the most common introductory student difficulty is to ignore the kinematics variables (axes) and read off the corresponding ordinate value for a given abscissa value rather than compute the slope, i.e., slope-height confusion (incorrect answer choices $E$ in both questions 6 and 17, selected by $36 \%$ and $44 \%$ of graduate students in this TUG-K related PCK task, but only $16 \%$ and $19 \%$ of introductory physics students as shown in Fig. 1). The performance of graduate students on the other two questions related to slopes in which there were common introductory student difficulties is better; however, there is room for improvement even in those contexts. On question 2, 52\% of graduate students identified the common difficulty of $37 \%$ of introductory students of confusing slope with height (see Table IV). On question 7, there were two common difficulties: the slope-height confusion (difficulty of $28 \%$ of introductory students, identified by $36 \%$ of graduate students as shown in Table IV) and not taking into account the scale of the $x$ and $y$ axes when determining the slope (difficulty of $20 \%$ of introductory students, identified by $28 \%$ of graduate students as shown in Table IV).

The performance of graduate students in identifying common introductory student difficulties related to determining areas under curves (including area-slope and areaheight confusion in Ref. [1]) is context dependent.

There are five questions on the TUG-K (items 1, 4, 10, 16 , and 18) which require students to determine the area under a particular graph and which reveal major or moderate introductory student difficulties. Table $\mathrm{V}$ shows that the performance of graduate students in identifying these difficulties is context dependent. On questions 1, 4, and 16 the vast majority of graduate students identified these 
TABLE IV. Introductory student difficulties related to determining slopes, items on the TUG-K which uncover these difficulties (TUG-K item no.), percentage of introductory students who answer the items incorrectly (\% overall incorrect), incorrect answer choices which uncover these difficulties, percentage of introductory students who have these difficulties based on their selection of these answer choices (intro. stud. diff.), and percentage of graduate students who select these answer choices as the most common incorrect answer choices of introductory students (GS \%). For convenience, short descriptions of the questions are given underneath.

\begin{tabular}{|c|c|c|c|c|c|}
\hline Introductory student difficulty & $\begin{array}{l}\text { TUG-K } \\
\text { item no. }\end{array}$ & $\begin{array}{l}\% \text { overall } \\
\text { incorrect }\end{array}$ & $\begin{array}{c}\text { Incorrect } \\
\text { answer choices }\end{array}$ & $\begin{array}{l}\% \text { intro. } \\
\text { stud. diff. }\end{array}$ & GS \% \\
\hline \multirow{2}{*}{$\begin{array}{l}\text { Determining slopes does not require examining initial } \\
\text { conditions }\end{array}$} & 6 & 74 & A & 46 & 20 \\
\hline & 17 & 79 & $\mathrm{~B}$ & 46 & 16 \\
\hline \multirow{2}{*}{$\begin{array}{l}\text { Slope-height confusion in Ref. [1] (i.e., reading off } \\
\text { the value from the vertical axis instead of computing } \\
\text { the slope appropriately) }\end{array}$} & 2 & 37 & $\mathrm{C}$ & 24 & 52 \\
\hline & 7 & 69 & $\mathrm{D}$ & 28 & 36 \\
\hline $\begin{array}{l}\text { Not taking into account the scales of the } x \text { and } y \text { axes } \\
\text { when determining slope (i.e., slope }=2 \text { units } / 1 \text { unit }= \\
2 \mathrm{~m} / \mathrm{s} \text { rather than } 2 \times 5 \mathrm{~m} / 1 \times 10 \mathrm{~s}=1 \mathrm{~m} / \mathrm{s} \text { ) on question } 7\end{array}$ & 7 & 69 & $\mathrm{~B}$ & 20 & 28 \\
\hline
\end{tabular}

2. Given velocity-time graph, identify at which point/interval the acceleration is most negative

6. Given a velocity-time graph, identify the acceleration at a particular time (must determine the slope of a straight line which does not go through the origin)

7. Given a velocity-time graph, identify the acceleration at a particular time (must estimate the slope of a straight line which does not pass through the origin)

17. Given displacement-time graph, identify the velocity at a particular time (must determine the slope of a straight line which does not go through the origin)

difficulties $(96 \%, 84 \%$, and $84 \%$ in questions 1 , 4, and 16 , respectively, as shown in Table V); however, on questions 10 and 18 , fewer graduate students identified the area-slope confusion of introductory students. This is interesting because questions 1 and 10 are posed in similar contexts: the five graphs of acceleration versus time are almost identical; the most salient difference is that question 1 asks for the greatest change in velocity, whereas question 16 asks for the smallest change in velocity. Although on question 1 graduate students overwhelmingly

TABLE V. Introductory student difficulties related to determining areas under curves, items on the TUG-K which uncover these difficulties (TUG-K item no.), percentage of introductory students who answer the items incorrectly (\% overall incorrect), incorrect answer choices which uncover these difficulties, percentage of introductory students who have these difficulties based on their selection of these answer choices (\% intro. stud. diff.), and percentage of graduate students who select these answer choices as the most common incorrect answer choices of introductory students (GS \%). For convenience, short descriptions of the questions are given underneath.

\begin{tabular}{|c|c|c|c|c|c|}
\hline Introductory student difficulty & TUG-K item no. & $\begin{array}{l}\% \text { overall } \\
\text { incorrect }\end{array}$ & $\begin{array}{l}\text { Incorrect answer } \\
\text { choices }\end{array}$ & $\begin{array}{l}\% \text { intro. } \\
\text { stud. diff. }\end{array}$ & GS $\%$ \\
\hline \multirow[t]{5}{*}{ Area-slope and/or area-height confusion } & 1 & 84 & $\mathrm{~A}, \mathrm{D}$ & 63 & 96 \\
\hline & 4 & 72 & $\mathrm{C}$ & 23 & 40 \\
\hline & 10 & 70 & $\mathrm{C}$ & 62 & 56 \\
\hline & 16 & 78 & $\mathrm{~B}, \mathrm{C}$ & 70 & 84 \\
\hline & 18 & 54 & $\mathrm{C}$ & 32 & 58 \\
\hline $\begin{array}{l}\text { Finding area by multiplying } y \times x \\
\text { (i.e., distance traveled by an object until } \\
\text { point }(3 \mathrm{~m} / \mathrm{s}, 2 \mathrm{~s}) \text { is } 6 \mathrm{~m}\end{array}$ & 4 & 72 & $\mathrm{E}$ & 32 & 44 \\
\hline
\end{tabular}

1. Given 5 acceleration vs time graphs, identify the graph in which the object has the greatest change in velocity during the time interval

4. Given a linearly increasing velocity vs time graph, identify the distance covered in the first few seconds

10. Given 5 acceleration vs time graphs, identify the graph in which the object has the smallest change in velocity during the time interval

16. Given a linearly increasing acceleration vs time graph, identify the object's change in velocity in the first few seconds

18. Given a linearly increasing velocity vs time graph, describe how you would find the distance covered in the first few seconds (read off $y$ value, find the area under line segment, find the slope, etc.) 
was of velocity versus time rather than position versus time (see Table VI). Few graduate students $(8 \%$ and $28 \%$, respectively) identify these answer choices as the most common incorrect choices of introductory students. Also, the PCK performance of graduate students on these two questions was the lowest among all TUG-K questions. During the whole class discussion after the task, many graduate students noted that they did not expect that introductory students would have this difficulty.

\section{SUMMARY}

In this research study, we explore one aspect of the pedagogical content knowledge of first-year graduate students enrolled in a TA training course at the end of the course as it relates to knowledge of student difficulties with kinematics graphs revealed by the TUG-K. Most of the graduate students were teaching recitations or labs for introductory physics courses, and out of the three that were not, two had experience as teaching assistants or tutors for introductory physics courses and one had tutored mathematics in their undergraduate career. For each question on the TUG-K, the graduate students were asked to identify the most common incorrect answer choice selected by introductory students who did not know the correct answer after instruction in relevant concepts. The graduate students first performed this task while working individually and then while working in groups of two or three after which there was a class discussion about the task and specific introductory student difficulties.

The ability to identify introductory student difficulties on the TUG-K does not appear to be dependent on familiarity with U.S. teaching practices.

We find that American graduate students who have been exposed to undergraduate teaching in the U.S. and had been taught physics in English do not perform better at identifying the most common introductory student difficulties than foreign graduate students. The discussions in the TA training class related to this TUG-K related PCK task suggest that the foreign graduate students were similar to American graduate students in this regard. However, it is difficult to explain why these groups exhibit comparable PCK performance when identifying common student difficulties with kinematic graphs as revealed by the TUG-K despite their different backgrounds.

Discussions among graduate students improved their $P C K$ performance in identifying common introductory student difficulties on the TUG-K.

The performance of graduate students in identifying introductory student difficulties with kinematics graphs as revealed by the TUG-K was significantly better when they worked in small groups compared to when they worked individually. In addition, when the individual answers of graduate students working in a group disagreed, discussions more often shifted towards the more common introductory student difficulty than the less common one. Furthermore, the class discussion with the graduate students after they performed the TUG-K related PCK tasks suggested that they found the tasks challenging but worthwhile. Many graduate students noted that they were surprised by the frequency of incorrect responses of introductory students in some of the questions and that they had not expected that introductory students would have certain difficulties with kinematics graphs. These findings suggest that performing individual and group activities about introductory student difficulties in the contexts of conceptual assessments like the TUG-K could prove to be beneficial in improving the pedagogical content knowledge related to common student difficulties of the participants and should be incorporated in professional development activities for TAs and instructors. In addition, this type of research should be carried out with other conceptual assessments to further explore the pedagogical content knowledge of instructors and/or teaching assistants related to understanding of common student difficulties in other areas.

Identifying some common introductory student difficulties related to kinematics graphs was very challenging for graduate students.

The three questions on the TUG-K with the highest discrimination indices (questions 11,14 , and 15) revealed a common introductory student difficulty that graphs of time dependence of different kinematics variables that correspond to the same motion should look the same. This difficulty was identified by very few graduate students. These questions have the highest discrimination indices according to Ref. [1] and introductory physics students who answered these questions correctly performed well on the whole test. Since these questions have the highest discrimination indexes, Beichner [1] noted that this difficulty might be the most critical to address to improve introductory students' understanding of graphs in the context of kinematics. However, we find that many graduate students are unaware that introductory students have this difficulty, and are therefore very unlikely to address this difficulty during instruction.

Another common difficulty of introductory students that determining slopes does not require examining initial conditions uncovered in questions 6 and 17 was identified by few graduate students. Graduate students were more likely to think that on these questions introductory students would read off the corresponding ordinate value for a given abscissa value instead of trying to compute the slope, which was a difficulty much less common among introductory students.

Another common difficulty in interpreting more complex graphs than straight-line graphs of introductory students in questions 8 and 9 is to match the verbal description of the motion superficially with a graph without regard for what the axes represent. For example, on question 8, which provided a displacement versus time graph, introductory students selected the verbal description which treated the graph as though it was of velocity versus time. Very few 
graduate students were aware of this difficulty and their average PCK performance on these questions was the lowest of all questions.

For the common introductory student difficulties which were uncovered in more than one question, the ability of graduate students to identify them was context dependent.

When examining the PCK performance of graduate students in identifying introductory student difficulties in particular contexts (such as determining areas under curves, determining slopes, interpreting graphs, etc.), we find that the ability of graduate students to identify the most common difficulties is almost always context dependent. For example, difficulties of introductory students related to determining areas under curves or difficulties related to determining slopes were identified by very few graduate students on some questions, but more graduate students on other contexts.

Graduate students, on average, exhibited lower PCK performance when identifying major introductory student difficulties on the TUG-K than when identifying moderate ones.
There are 17 questions on the TUG-K which uncover moderate (nine questions) or major (eight questions) introductory student difficulties, and the graduate students performed better than random guessing on eight of these 17 questions. Moreover, graduate students had more difficulty in identifying major difficulties compared to moderate difficulties of introductory students. Furthermore, the analysis of the PCK score of the graduate students (as a percentage of the maximum possible score) on each question shows that, on all four questions on which the average PCK score of graduate students was the lowest, there were major introductory student difficulties.

This result can be interpreted to mean that it is challenging to identify what introductory students would find difficult in a particular context. In other words, it is challenging for instructors to understand their students' perspective on what specific aspects of physics are difficult unless they have explicitly focused on these issues on student difficulties in their own classes or are familiar with physics education research which discusses student difficulties.

\begin{tabular}{|c|c|c|c|c|c|c|c|c|c|c|c|c|}
\hline \multirow{2}{*}{$\begin{array}{l}\text { TUG-K } \\
\text { item no. }\end{array}$} & \multirow[t]{2}{*}{$>\mathrm{RG}$} & \multicolumn{5}{|c|}{ Intro. stud. choices } & & \multicolumn{5}{|c|}{ Grad student choices } \\
\hline & & A & B & C & D & $\mathrm{E}$ & & A & B & $\mathrm{C}$ & $\mathrm{D}$ & $\mathrm{E}$ \\
\hline 1 & Yes & 41 & 16 & 4 & 22 & 17 & 1 & 36 & 0 & 0 & 60 & 4 \\
\hline 2 & Yes & 2 & 10 & 24 & 2 & 63 & 2 & 0 & 40 & 52 & 4 & 4 \\
\hline 3 & Yes & 8 & 0 & 20 & 62 & 10 & 3 & 24 & 0 & 72 & 0 & 4 \\
\hline 4 & Yes & 2 & 14 & 23 & 28 & 32 & 4 & 0 & 16 & 40 & 0 & 44 \\
\hline 6 & No & 46 & 26 & 6 & 6 & 16 & 6 & 20 & 4 & 20 & 20 & 36 \\
\hline 7 & No & 31 & 20 & 10 & 28 & 10 & 7 & 0 & 28 & 28 & 36 & 8 \\
\hline 8 & No & 11 & 11 & 37 & 37 & 5 & 8 & 40 & 40 & 8 & 4 & 8 \\
\hline 9 & No & 7 & 57 & 5 & 7 & 24 & 9 & 40 & 28 & 16 & 12 & 4 \\
\hline 10 & Yes & 30 & 2 & 62 & 3 & 3 & 10 & 12 & 4 & 56 & 28 & 0 \\
\hline 11 & No & 28 & 17 & 11 & 36 & 8 & 11 & 8 & 64 & 8 & 8 & 12 \\
\hline 14 & No & 25 & 48 & 15 & 9 & 3 & 14 & 16 & 0 & 28 & 56 & 0 \\
\hline 15 & No & 29 & 24 & 13 & 8 & 26 & 15 & 8 & 8 & 16 & 16 & 52 \\
\hline 16 & Yes & 1 & 39 & 31 & 22 & 7 & 16 & 4 & 16 & 68 & 4 & 8 \\
\hline 17 & No & 21 & 46 & 8 & 7 & 19 & 17 & 4 & 16 & 16 & 20 & 44 \\
\hline 18 & Yes & 7 & 46 & 32 & 4 & 10 & 18 & 17 & 4 & 58 & 0 & 21 \\
\hline 19 & No & 19 & 9 & 37 & 12 & 23 & 19 & 21 & 13 & 4 & 13 & 50 \\
\hline 21 & Yes & 18 & 73 & 2 & 5 & 2 & 21 & 4 & 79 & 8 & 8 & 0 \\
\hline \multicolumn{13}{|c|}{$\begin{array}{l}\text { Correct answer } \\
x>33-\text { major } d\end{array}$} \\
\hline $\mathrm{x}$ & \multirow{2}{*}{\multicolumn{12}{|c|}{$\begin{array}{l}x>33- \\
20 \leq x \leq\end{array}$}} \\
\hline $\mathrm{X}$ & & & & & & & & & & & & \\
\hline
\end{tabular}

FIG. 1 (color online). Questions on the TUG-K in which at least $20 \%$ of introductory students selected an incorrect answer choice in a posttest, percentages of introductory physics students (Intro. stud. choices) who selected each answer choice A through E in a posttest (they were asked to select the correct answer for each question), and graduate students (Grad student choices) who selected each answer choice A through E (they were asked to select the most common incorrect answer for each question if introductory students did not know the correct answer). The first column of the table lists the TUG-K question numbers and the second column (titled $>$ RG) indicates whether the graduate students on average performed better than random guessing. 
The graduate students learned in introductory physics at least three or four years prior to this study and they may have lost track of what they found confusing during the learning process. It is even possible that most graduate students are not typical introductory physics students and did not have the same difficulties that many introductory students have. Therefore, activities like the one presented here, especially if they are designed to promote discussions about student difficulties, can prove valuable in preparatory courses for prospective physics instructors.

\section{APPENDIX: MATHEMATICAL DESCRIPTION OF HOW THE TUG-K RELATED PCK SCORES WERE CALCULATED}

We define indices $i, j$, and $k$ that correspond to the following:
- $i$, index of graduate student (25 graduate students; it takes values from 1 to 25);

- $j$, TUG-K question number (21 questions; it takes values from 1 to 21);

- $k$, incorrect answer choice number (4 incorrect answer choices; it takes values from 1 to 4 ).

Then, let $F_{j k}$ be the fraction of introductory physics students who select incorrect answer choice $k$ on item $j$ (e.g., $F_{11}=0.4, F_{12}=0.04, F_{13}=0.22, F_{14}=0.17$ ). Let $G S_{i j k}$ correspond to whether graduate student $i$ selected incorrect answer choice $k$ on item $j$ (for a given graduate student $i$ and TUG-K item $j, G S_{i j k}=1$ only for the incorrect answer choice $k$, selected by graduate student $i$ on item $j$, otherwise $G S_{i j k}=0$ ). Then, the PCK score of the $i$ th graduate student on item $j$ (referred to $G S_{i j}$ ) is $G S_{i j}=\sum_{k=1}^{4}\left(G S_{i j k} \times F_{j k}\right)$. Then, the PCK score of the $i$ th

\begin{tabular}{|l|l|l|l|l|l|}
\hline $\begin{array}{l}\text { TUG-K } \\
\text { item no. }\end{array}$ & $\begin{array}{l}\text { \% intro. } \\
\text { correct }\end{array}$ & $\begin{array}{l}\text { Min. pos. } \\
\text { PCK } \\
\text { score }\end{array}$ & $\begin{array}{l}\text { Max. pos. } \\
\text { PCK } \\
\text { score }\end{array}$ & $\begin{array}{l}\text { GS avg. } \\
\text { PCK score }\end{array}$ & $\begin{array}{l}\text { Norm. GS } \\
\text { avg. PCK } \\
\text { score }\end{array}$ \\
\hline 1 & 16 & 0.04 & 0.41 & 0.29 & 68 \\
\hline 2 & 63 & 0.02 & 0.24 & 0.17 & 68 \\
\hline 3 & 62 & 0.00 & 0.20 & 0.17 & 85 \\
\hline 4 & 28 & 0.02 & 0.32 & 0.26 & 80 \\
\hline 6 & 26 & 0.06 & 0.46 & 0.17 & 28 \\
\hline 7 & 31 & 0.10 & 0.28 & 0.19 & 50 \\
\hline 8 & 37 & 0.05 & 0.37 & 0.12 & 22 \\
\hline 9 & 24 & 0.05 & 0.57 & 0.20 & 29 \\
\hline 10 & 30 & 0.02 & 0.62 & 0.36 & 57 \\
\hline 11 & 36 & 0.08 & 0.28 & 0.15 & 35 \\
\hline 14 & 48 & 0.03 & 0.25 & 0.13 & 45 \\
\hline 15 & 29 & 0.08 & 0.26 & 0.19 & 61 \\
\hline 16 & 22 & 0.01 & 0.39 & 0.28 & 71 \\
\hline 17 & 21 & 0.07 & 0.46 & 0.18 & 28 \\
\hline 18 & 46 & 0.04 & 0.32 & 0.22 & 64 \\
\hline 19 & 37 & 0.09 & 0.23 & 0.18 & 64 \\
\hline 21 & 18 & 0.02 & 0.73 & 0.58 & 79 \\
\hline
\end{tabular}

no. Question in which there was a moderate difficulty

no. Question in which there was a major difficulty

$\begin{array}{ll}\mathrm{x} & \text { Grad students' TUG-K related PCK score is less than } 1 / 2 \text { of maximum possible } \\ \mathrm{x} & \text { Grad students' TUK-K related PCK score is between } 1 / 2 \text { and } 2 / 3 \text { of maximum possible } \\ \mathrm{x} & \text { Grad students' TUG-K related PCK score is more than } 2 / 3 \text { of maximum possible }\end{array}$

FIG. 2 (color online). Questions on the TUG-K on which at least $20 \%$ of introductory students selected one incorrect answer choice after instruction, percentages of introductory students who answered each question correctly (\% intro. correct), minimum possible TUG-K related PCK score (Min. pos. PCK score), maximum possible TUG-K related PCK score (Max. pos. PCK score), graduate students' average PCK score (GS avg. PCK score), graduate students' normalized average PCK score on a scale from 0 to 100 (Norm. GS avg. PCK score). 
graduate student on the whole survey $\left(G S_{i}\right)$ can be obtained by summing over all the questions:

$$
G S_{i}=\sum_{j=1}^{21} G S_{i j}=\sum_{j=1}^{21}\left[\sum_{k=1}^{4}\left(G S_{i j k} \times F_{j k}\right)\right] .
$$

Also, the average score of all the graduate students on item $j$ (referred to as $\overline{G S_{j}}$ ) is

$$
\overline{G S_{j}}=\frac{1}{25} \sum_{i=1}^{25} G S_{i j}=\frac{1}{25} \sum_{i=1}^{25}\left[\sum_{k=1}^{4}\left(G S_{i j k} \times F_{j k}\right)\right] .
$$

A similar approach can be adopted for random guessing:
- $R G_{i j}=P C K$ score of $i$ th random guesser on item $j$;

- $R G_{i}=P C K$ score of $i$ th random guesser;

- $\overline{R G_{j}}=P C K$ score of random guessing on item $j$ ).

The PCK score of each graduate student and random guesser $\left(G S_{i}, R G_{i}\right.$ as described above) were used to obtain averages and standard deviations in order to perform $t$-tests to compare the performance of graduate students with random guessing on the whole survey (and to compare different subgroups of graduate students).

In order to compare the performance of these different groups on individual items, the averages and standard deviations of the PCK scores on that particular item (e.g., for question $j$ on the TUG-K, $G S_{i j}, R G_{i j}$ ) were used to perform $t$-tests.
[1] R. Beichner, Testing student interpretation of kinematics graphs, Am. J. Phys. 62, 750 (1994).

[2] D. Hestenes, M. Wells, and G. Swackhammer, Force Concept Inventory, Phys. Teach. 30, 141 (1992).

[3] I. Halloun, R. R. Hake, E. P. Mosca, and D. Hestenes, Force Concept Inventory, online (password protected) at http://modeling.asu.edu/R\%26E/Research.html, revised 1995; see also E. Mazur, Peer Instruction: A User's Manual (Prentice-Hall, Englewood Cliffs, NJ, 1997).

[4] R. Thornton and D. Sokoloff, Assessing student learning of Newton's laws: The Force and Motion Conceptual Evaluation, Am. J. Phys. 66, 338 (1998).

[5] P. Nieminen, A. Savinainen, and J. Viiri, Force Concept Inventory-based multiple-choice test for investigating students' representational consistency, Phys. Rev. ST Phys. Educ. Res. 6, 020109 (2010).

[6] D. Hestenes and M. Wells, A mechanics baseline test, Phys. Teach. 30, 159 (1992).

[7] G. L. Gray, F. Constanzo, D. Evans, P. Cornwell, B. Self, and J.L. Lane, in Proceedings of the 2005 American Society for Engineering Education Annual Conference, Portland, OR, 2005, http://www.esm.psu.edu/dci/papers/ ASEE-DCI-Portland.pdf.

[8] J. Mitchell, J. Martin, and T. Newell, Development of a concept inventory for fluid mechanics, Proc. Front. Educ. Conf. 1, T3D-23 (2003).

[9] M. C. Wittman, Ph.D. thesis, University of Maryland, 1998.

[10] A. Tongchai, M.D. Sharma, I.D. Johnston, K. Arayathanitkul, and C. Soankwam, Developing, evaluating and demonstrating the use of a conceptual survey of mechanical waves, Int. J. Sci. Educ. 31, 2437 (2009).

[11] L. Ding, R. Chabay, B. Sherwood, and R. Beichner, Evaluating an electricity and magnetism assessment tool: Brief electricity and magnetism assessment, Phys. Rev. ST Phys. Educ. Res. 2, 010105 (2006).

[12] E. Mazur, Peer Instruction: A User's Manual (PrenticeHall, Englewood Cliffs, NJ, 1997).

[13] R. R. Hake, Interactive-engagement versus traditional methods: A six-thousand-student survey of mechanics test data for introductory physics courses, Am. J. Phys. 66, 64 (1998).

[14] M.H. Dancy, Ph.D. thesis, North Carolina State University, 2000.

[15] J. Docktor and K. Heller, Gender differences in both Force Concept Inventory and Introductory Physics Performance, AIP Conf. Proc. 1064, 15 (2008).

[16] Fred M. Goldberg and John H. Anderson, Student difficulties with graphical representation of negative velocity, Phys. Teach. 27, 254 (1989).

[17] J.R. Mokros and R.F. Tinker, The impact of microcomputer-based labs on children's ability to interpret graphs, J. Res. Sci. Teach. 24, 369 (1987).

[18] L.C. McDermott, M.L. Rosenquist, and E. H. van Zee, Student difficulties in connecting graphs and physics: Examples from kinematics, Am. J. Phys. 55, 503 (1987).

[19] E. H. van Zee and L. C. McDermott, in Proceedings of the Second International Seminar on Misconceptions and Educational Strategies in Science and Mathematics, Ithaca, NY, 1987, http://eric.ed.gov/?id=ED293686, pp. 531-539.

[20] W.L. Barclay, in Proceedings of the 1986 National Educational Computing Conference, San Diego, 1986 (Technical Education Research Center Technical Report No. TERC-TR-85-5, 1986).

[21] R. Thornton and D. Sokoloff, Learning motion concepts using real-time microcomputer-based laboratory tools, Am. J. Phys. 58, 858 (1990).

[22] J. Larkin, in Research in Science Education: New Questions, New Directions, edited by J. Robinson (Center for Educational Research and Evaluation, Louisville, CO, 1981), pp. 115-130.

[23] A. B. Arons, Student patterns of thinking and reasoning, Part three, Phys. Teach. 22, 88 (1984).

[24] D. E. Trowbridge and L.C. McDermott, Investigation of student understanding of the concept of acceleration in one dimension, Am. J. Phys. 49, 242 (1981).

[25] Z. Chen, T. Stelzer, and G. Gladding, Using multimedia modules to better prepare students for introductory 
physics lecture, Phys. Rev. ST Phys. Educ. Res. 6, 010108 (2010).

[26] T. Stelzer, D. R. Brookes, G. Gladding, and J. P. Mestre, Impact of multimedia learning modules on an introductory course on electricity and magnetism, Am. J. Phys. 78, 755 (2010).

[27] H. R. Sadaghiani, Using multimedia learning modules in a hybrid-online course in electricity and magnetism, Phys. Rev. ST Phys. Educ. Res. 7, 010102 (2011).

[28] H. Ginsberg and S. Opper, Piaget's Theory of Intellectual Development (Prentice-Hall, Englewood Cliffs, NJ, 1969).

[29] G. J. Posner, K. A. Strike, P. W. Hewson, and W. A. Gertzog, Accommodation of a scientific conception: Toward a theory of conceptual change, Sci. Educ. 66, 211 (1982).

[30] L. S. Shulman, Those who understand: Knowledge growth in teaching, Educ. Res. 15, 4 (1986).

[31] L.S. Shulman, Knowledge and teaching: Foundations of the new reform, Harv. Educ. Rev. 57, 1 (1987).

[32] J. H. van Driel, N. Verloop, and W. de Vos, Developing science teachers pedagogical content knowledge, J. Res. Sci. Teach. 35, 673 (1998).

[33] P.L. Grossman, in Advances in Research on Teaching: Subject Matter Knowledge, edited by J.
Brophy (JAI Press, Greenwich, CT, 1991), Vol. 2, pp. 245-264.

[34] J. Gess-Newsome and N.G. Lederman, Examining Pedagogical Content Knowledge (Kluwer Academic, Boston, 2001).

[35] J. Loughran, P. Mulhall, and A. Berry, In search of pedagogical content knowledge in science: Developing ways of articulating and documenting professional practice, J. Res. Sci. Teach. 41, 370 (2004).

[36] E. Etkina, Pedagogical content knowledge and preparation of high school physics teachers, Phys. Rev. ST Phys. Educ. Res. 6, 020110 (2010).

[37] Available at http://www.aip.org/statistics/trends/highlite/ edphysgrad/table1b.htm.

[38] Available at http://www.aip.org/statistics/trends/highlite/ edphysgrad/figure 7.htm.

[39] C. Singh, in Proceedings of the Physics Education Research Conference, Boise, ID, 2002, edited by S. Franklin, J. Marx, and K. Cummings (AIP, Melville, NY, 2002).

[40] G. V. Glass and K. D. Hopkins, Statistical Methods in Education \& Psychology (Allyn \& Bacon, Boston, MA 1996). 